\title{
Três anos de acidentes do trabalho em uma metalúrgica: caminhos para seu entendimento
}

\author{
Three years of work-related accidents in a metallurgic plant: \\ ways to its understanding
}

Cláudia Giglio de Oliveira Gonçalves ${ }^{1}$

Adriano Dias ${ }^{2}$

${ }^{1}$ Faculdade de Ciências Biológicas e da Saúde, Universidade Tuiuti do Paraná. Rua Sydnei Antonio Rangel Santos 236. 82010-330 Curitiba PR clgiglio@terra.com.br ${ }^{2}$ Faculdade de Medicina de Botucatu, Universidade Estadual Paulista.

\begin{abstract}
The objective of this study is to describe, by quantitative and qualitative methods, industrial accidents occurred during three years in a metallurgic plant in the rural area to understand the possible causes. It is a case study in a metallurgic plant where 336 accidents were studied in a 3year period by means of three procedures: analysis of accidents' registers, interviews with 166 hurt workers, and the organization of Focal Groups (111 workers) for discussion. The ratio of yearly incidence of accidents was 16.9\%; 75 cases required more than 15 out-of-work days; $51.2 \%$ occurred in the morning and affected boilermakers (48.2\%). Among the interviewed workers, average schooling was 8.8 years, age ranged from 31-50 years (55.4\%), 64.5\% of workers had already suffered more than one accident. Besides, workers exposed to intense noise (+90 dBA) were the most affected (53\%). In the focal groups, perceptions and feelings of workers regarding the accidents were identified that had not appeared in the previous stages. It can be concluded that focal groups allow for a better identification of factors that may contribute for accidents such as performance pressures, extra-hours of work, low wages, and precarious conditions of work and work organization.
\end{abstract}

Key words Occupational health, Occupational accidents, Occupational risks
Resumo O objetivo deste artigo é descrever, através de estratégias metodológicas quantitativas e qualitativas, os acidentes do trabalho ocorridos em três anos numa indústria metalúrgica do interior de São Paulo para compreender suas possíveis causas. Trata-se de um estudo de casos de uma indústria; foram estudados 336 acidentes em três anos, utilizando-se três procedimentos: análise dos registros dos acidentes, entrevistas (166 acidentados) e realização de grupos focais (111 trabalhadores). A proporção de incidência anual dos acidentes foi de 16,9\%; 75 casos com afastamento superior a 15 dias; 51,2\% ocorreram pela manhã, afetando caldeireiros (48,2\%). Entre os entrevistados, escolaridade média de 8,8 anos e idade de 31 a 50 anos (55,4\%); 64,5\% já haviam sofrido outros acidentes e com maior ocorrência naqueles expostos ao ruído intenso (mais $90 \mathrm{dBA}$ ) (53\%). Nos grupos focais, identificaram-se percepções e sentimentos dos trabalhadores a respeito dos acidentes que não apareceram nas etapas anteriores. Através dos grupos focais pode-se identificar melhor os fatores que contribuem para os acidentes, como: pressões, realização de horas extras, baixos salários, condições de trabalho precárias e organização do trabalho.

Palavras-chave Saúde ocupacional, Acidentes de trabalho, Riscos ocupacionais 


\section{Introdução}

Os novos avanços tecnológicos e a globalização contribuíram com inovações nas formas de produção, trazendo mudanças para o mundo do trabalho, mas geraram como subproduto os acidentes do trabalho ${ }^{1}$.

A acidentabilidade no trabalho está associada a diversos fatores, como os problemas na organização do trabalho, a negligência às situações de exposição ou a sua determinação social ${ }^{2-5}$.

Tradicionalmente, a análise dos acidentes de trabalho é realizada com base numa concepção "unicausal", na qual as causas dos acidentes estão centradas no fator técnico ou humano, ou numa concepção "multicausal", na qual os acidentes são resultantes da interação entre o operador e outros componentes da situação de trabalho, além dos fatores técnicos e humanos. Seguindo essas abordagens, uma das teorias explicativas dos acidentes de trabalho mais antiga é a Teoria da Propensão ao Acidente, criticada como possuidora de um caráter ideológico por atribuir a culpa das ocorrências dos acidentes ao próprio trabalhador ${ }^{6}$. Somente mais recentemente, alguns pesquisadores vêm adotando uma concepção "sistêmica", na qual os acidentes são fenômenos complexos e pluricausais, reveladores de uma disfunção na empresa, que é considerada como um sistema sociotécnico aberto, como na Teoria dos Sistemas, que enfatiza a importância de se considerar os fatores da organização do trabalho e gerenciais na gênese dos acidentes ${ }^{7}$.

Apesar dessa nova visão sobre os acidentes e das contribuições teórico-metodológicas alcançadas com o delineamento da área da Saúde do Trabalhador, ainda predomina, nas empresas, uma visão limitada, numa perspectiva uni ou multicausal, a analisar os fatores de risco presentes predominantemente no ambiente físico do trabalho e atribuindo ao trabalhador a culpa pelo acidente (culpabilização da vítima $)^{8}$.

Na perspectiva da Saúde do Trabalhador, busca-se romper com essa ideia de um vínculo causal entre a doença/acidentes de trabalho e fatores de risco presentes exclusivamente no ambiente físico de trabalho, para também investigar os componentes derivados da organização do trabalho, com características mais qualitativas, analisando-se os esforços exigidos pela organização e pela atividade de trabalho. Assim, tornase essencial a valorização da subjetividade do trabalhador, como sujeito capaz de pensar e de se pensar no trabalho, proporcionando outro olhar para as questões dos acidentes ${ }^{8,9}$.
Nesse sentido, os acidentes de trabalho são resultantes de uma complexa interação entre aspectos físicos, psicológicos e sociais imprescindíveis para a sua compreensão ${ }^{10}$.

A análise dos acidentes de trabalho, que inclua a investigação das situações de risco e seus determinantes tecnológicos e sociais, é uma tarefa difícil aos profissionais da saúde que precisam utilizar novos métodos investigativos. Porém, se faz necessária principalmente para a orientação de propostas que visem a intervenções para a sua redução ${ }^{11}$.

A adoção de estratégias de investigação combinadas entre abordagens qualitativas e quantitativas vem sendo difundida. A interlocução com os próprios trabalhadores é também uma estratégia importante, reconhecendo-se suas experiências e saberes em relação ao trabalho ${ }^{8}$.

Os acidentes de trabalho, além de gerarem prejuízo aos trabalhadores e empregadores, afetam a economia do país, sendo um importante problema de saúde pública que depende de melhor compreensão para ser controlado. Mas é difícil conhecer-se a magnitude do problema, pois mesmo com um aparato legal no país para que os acidentes de trabalho sejam notificados e a informação produzida norteie as ações na promoção e na prevenção de danos à saúde dos trabalhadores, a subnotificação é uma realidade e dificulta o conhecimento, pelas autoridades competentes, das reais condições em que o trabalho se desenvolve, desqualificando os direitos sociais e securitários ao trabalhador ${ }^{12-16}$.

A Comunicação de Acidente do Trabalho (CAT) é obrigatória para fins de registro e não necessariamente para o afastamento do trabalho, mas nem sempre acontece. No caso dos acidentes leves, que não geram afastamento do trabalho ou o afastamento é inferior a quinze dias, a subnotificação é mais constante ${ }^{17}$.

O objetivo deste trabalho é descrever, através de estratégias metodológicas quantitativas e qualitativas, os acidentes de trabalho ocorridos em três anos numa indústria metalúrgica do interior de São Paulo para compreender suas possíveis causas, orientando ações preventivas.

\section{Método}

Trata-se de um estudo de caso descritivo, que utilizou métodos qualitativos e quantitativos para compreender as possíveis causas de acidentes de trabalho ocorridos em três anos numa indústria metalúrgica. 
Optou-se pela utilização de abordagens quantitativas e qualitativas para a coleta de dados, por se considerar que devido à complexidade de fatores envolvidos na gênese dos acidentes de trabalho, a utilização de uma única abordagem não seria suficiente para a investigação, portanto ambas as abordagens foram utilizadas como complementares uma da outra. No entanto, não foi objeto deste estudo uma análise por triangulação de métodos.

A empresa estudada foi uma indústria metalúrgica de médio porte, fabricante de máquinas e equipamentos, classificada com grau de risco 3, certificada pela norma ISO 9000, localizada no interior de São Paulo.

Foram estudados 336 acidentes do trabalho ocorridos entre os 662 trabalhadores da área fabril, no período de janeiro de 2003 a dezembro de 2005, através de três procedimentos: levantamento de documentos da empresa, aplicação de questionário com questões fechadas aos acidentados e formação de grupos focais com os trabalhadores acidentados voluntários.

Realizou-se, inicialmente, a análise documental do Programa de Prevenção de Riscos Ambientais (PPRA), do mapa de riscos e do Programa de Controle Médico de Saúde Ocupacional (PCMSO) para o período estudado, a fim de se conhecer os principais agentes presentes no ambiente fabril e que poderiam contribuir como fatores de risco para a ocorrência dos acidentes, e as medidas adotadas para a sua prevenção. Além disso, coletaram-se as seguintes informações referentes a cada acidente, registradas pelo ambulatório de saúde da empresa: setor e função do trabalhador acidentado, data e hora do acidente, lesão e parte do corpo atingida e gravidade do acidente (medida pela presença ou ausência de afastamento e pela abertura de CAT).

Num segundo momento, no mês subsequente à ocorrência dos acidentes, foi aplicado um questionário com perguntas fechadas a 166 acidentados para investigar os possíveis fatores que influenciaram nos acidentes. Essa população foi definida considerando-se uma amostra de vigilância populacional em uma população finita de 336 sujeitos acidentados, para uma frequência antecipada de $50 \%$, com probabilidade de erro de $+/-5 \%$, que resultou na necessidade de avaliação de 165 sujeitos, selecionados aleatoriamente por sorteio computacional ${ }^{18}$. Para esses indivíduos, além dos dados coletados pelo serviço de saúde da empresa, somaram-se as seguintes informações: idade, escolaridade, intensidade do ruído a que estavam expostos, percepção do ru- ído e a ocorrência anterior de acidentes. Os dados foram processados no software SPSS (versão 15) para análise estatística.

No terceiro momento, foram realizados encontros com alguns trabalhadores numa proposta de grupo focal, considerando-se que o próprio trabalhador é depositário de um saber que vem das suas experiências e que, ao serem compartilhadas no grupo, podem despertar a elaboração de percepções que ainda se mantinham latentes. Dentre os 166 trabalhadores entrevistados e que foram convidados a participar dessa terceira fase, 111 aderiram voluntariamente e compuseram os grupos focais. O grupo focal é uma técnica que tem por objetivo a caracterização qualitativa de dados em pesquisas e processos diagnósticos ou avaliativos ${ }^{19,20}$. Foram organizados grupos de 6 a 17 trabalhadores, em reuniões que duravam uma hora, realizadas na própria empresa, conduzidas por um moderador (o próprio pesquisador) e registradas por dois relatores (profissionais da área da saúde familiarizados com o método do grupo focal), abordando a descrição das prováveis causas dos acidentes na fábrica e sugestões para a diminuição da ocorrência desses acidentes. Não houve a participação de representantes da empresa nos grupos, propiciando melhores condições de livre expressão aos trabalhadores acidentados. Nessa fase, buscou-se compreender como o grupo de trabalhadores percebia a ocorrência dos acidentes do trabalho, explicitando que a falta de consenso não refletiria entendimento inadequado, mas a gênese multifatorial da ocorrência. Os resultados dessa etapa foram organizados de modo a se compreender como o grupo percebia o foco do estudo, sendo apresentados por meio de conjuntos temáticos, identificados pela categorização da discussão.

Para a análise dos resultados, procedeu-se à descrição e comparação de dados coletados por métodos qualitativos e quantitativos, e tomaramse como base aspectos classicamente abordados pela Saúde do Trabalhador na explicação dos acidentes do trabalho, de maneira coletiva.

\section{Resultados}

\section{Caracterização pelos documentos da empresa}

A empresa estudada manteve uma população em torno de 662 trabalhadores na área fabril entre os anos de 2004 e 2006. No PPRA da em- 
presa, foram identificados como principais riscos os agentes físicos: ruído, calor e radiações não ionizantes; agentes químicos como fumos metálicos e produtos químicos; agentes ergonômicos como trabalho noturno fixo e postura inadequada; agentes mecânicos como animais peçonhentos, queda de diferença de nível, batidas, cortes, prensamento, impacto de objetos, eletricidade, queimaduras e máquinas ou equipamentos sem proteção. Como medidas de controle desses agentes, há indicação para adequar o ambiente sem, no entanto, apontar quais seriam as adequações necessárias. A utilização e o monitoramento do uso de equipamentos de proteção individual e a orientação sobre segurança aos trabalhadores foram constantes para cada risco.

No mapa de risco da empresa, realizado pelos integrantes da Comissão Interna de Prevenção de Acidentes (Cipa) a cada dois anos, foram identificados como grupos de agentes de riscos de alta gravidade os riscos físicos: ruído (presente em todos os setores fabris); radiações não ionizantes, no setor de caldeiraria; e os riscos químicos: poeira, fumos e gases, no setor de caldeiraria. Os riscos de acidentes, considerados de média gravidade, foram o risco de incêndio e explosões, choque elétrico, com animais peçonhentos, maquinário perigoso e pela iluminação inadequada (em alguns setores).

A empresa tem Serviço de Segurança e Medicina do Trabalho (SESMT) próprio, além de convênio com empresa de medicina de grupo para o encaminhamento dos funcionários que necessitem de procedimentos não disponíveis no ambulatório da empresa. Não foram encontradas referências sobre a utilização dos serviços públicos de saúde. No PCMSO, foi encontrada a indicação de realização de exames clínicos e exames complementares, de acordo com os riscos de cada função. Segundo os relatórios do PCMSO, os problemas críticos de saúde na empresa são as alterações auditivas e doenças osteomusculares como as epicondilites e bursites.
Não se observou descrição de procedimentos de emergência a serem adotados em caso de acidentes. Existem equipes de trabalhadores treinados como socorristas e uma ambulância própria para conduzir o acidentado ao hospital conveniado, quando necessário. Somente os acidentes com afastamento geravam a abertura da CAT. Observou-se a existência de um Programa de Conservação Auditiva implantado, contemplando ações de monitoramento auditivo para todos os trabalhadores fabris através de exames audiológicos (há em torno de $36 \%$ de trabalhadores com perda auditiva sugestiva de indução por ruído), ações educativas visando à conscientização sobre os efeitos do ruído e de como proteger-se deste e a indicação de ações sobre o ambiente de trabalho, evidenciando os pontos críticos em relação ao ruído. Não se encontraram, no entanto, indicações do controle do ruído na fonte ou no trajeto, e as medidas adotadas se restringiam à proteção dos trabalhadores através da utilização de protetores auriculares, atingindo $100 \%$ de adesão nos setores fabris.

No período de três anos, ocorreram 336 acidentes de trabalho, distribuídos conforme a Tabela 1 .

No que se refere ao tipo de lesão, encontrouse o predomínio de contusões e ferimentos corto-contusos $(74,7 \%)$, seguidos de queimaduras $(9,8 \%)$, fraturas $(4,2 \%)$ e escoriações $(3 \%)$. Mais de $57 \%$ dos acidentes atingiram os membros superiores, $16 \%$ os membros inferiores e $16 \%$ regiões da cabeça, com predominância do lado esquerdo do corpo $(47,6 \%)$.

A Tabela 2 mostra as funções desempenhadas pelos trabalhadores acidentados.

A maioria dos acidentes $(51,2 \%)$ ocorreu pela manhã (no período que se estende das $6 \mathrm{~h}$ às $12 \mathrm{~h}$ ), enquanto $35,4 \%$ ocorreram à tarde (entre $12 \mathrm{~h} \mathrm{e}$ $18 \mathrm{~h}), 6,8 \%$ à noite ( $18 \mathrm{~h}$ à $0 \mathrm{~h}$ ) e $6,5 \%$ na madrugada ( $0 \mathrm{~h}$ às $6 \mathrm{~h}$ ).

A exposição aos níveis de pressão sonora (NPS), identificados nos documentos da empre-

Tabela 1. Distribuição e caracterização dos acidentes de trabalho de 2004 a $2006(n=336)$.

\begin{tabular}{lccrr}
\hline & $\mathbf{2 0 0 4}$ & $\mathbf{2 0 0 5}$ & $\mathbf{2 0 0 6}$ & Total \\
\hline Casos & $106(31,6 \%)$ & $126(37,5 \%)$ & $104(30,9 \%)$ & 336 \\
Proporção de incidência (\%) & 16,01 & 19,03 & 15,70 & 16,91 \\
Emissão de CAT & 33 & 30 & 19 & 82 \\
Com afastamento (mais de 15 dias) & 20 & 30 & 25 & 75 \\
\hline
\end{tabular}


sa como risco grave presente em toda a fábrica, que expõem os trabalhadores acidentados, está na Tabela 3.

Em 42 trabalhadores, foram registrados mais de um acidente no período. Dentre esses, observaram-se 34 trabalhadores que sofreram acidente por duas vezes e casos que se acidentaram mais de três vezes, caracterizados na Tabela 4 segundo a exposição ao nível de pressão sonora (NPS) e função.

Não foi observada significância estatística na associação entre o NPS e a gravidade do acidente

Tabela 2. Funções dos trabalhadores com maior ocorrência de acidentes, no período de 2004 a 2006 $(n=336)$.

\begin{tabular}{lcc}
\hline \multicolumn{1}{c}{ Função } & $\begin{array}{c}\text { Freq. } \\
\text { absoluta }\end{array}$ & $\begin{array}{c}\text { Freq. } \\
\text { relativa (\%) }\end{array}$ \\
\hline Caldeireiro & 162 & 48,2 \\
Soldador & 72 & 21,4 \\
Praticante de caldeireiro & 17 & 5,1 \\
Operador de máquina de & 12 & 3,6 \\
produção & 10 & 3,0 \\
Maçariqueiro & 6 & 1,8 \\
Mecânico de manutenção & 5 & 1,5 \\
Lavador de peças & 5 & 1,5 \\
Furador & 47 & 13,9 \\
Outras & & \\
\hline
\end{tabular}

$(\mathrm{p}=0,852)$ ou a reincidência do acidente do trabalho $(\mathrm{p}=1,000)$.

Os exames audiométricos mostraram que 37,20\% (125) dos acidentados apresentavam audiograma sugestivo de perda auditiva induzida por ruído (PAIR) e 5,05\% apresentavam alterações auditivas provavelmente não associadas ao ruído.

\section{Etapa 2: questionário aplicado numa amostra de 166 trabalhadores}

Dos 366 trabalhadores acidentados, 166 indivíduos foram submetidos a um questionário. A média de anos de escolaridade no grupo entrevistado foi de 8,8 anos ( $\mathrm{DP}= \pm 2,4$, com mínimo de 3 e máximo de 11 , mediana $=9$ e moda $=11$ anos), com predomínio na faixa de 5 a 8 anos (22,9\%).

Quanto à distribuição da idade, observou-se que quase $40 \%$ possuíam até 30 anos de idade; no entanto, mais da metade da ocorrência dos acidentes se deu na faixa de 31 a 50 anos $(55,4 \%)$.

A maioria $(64,5 \%)$ dos trabalhadores entrevistados já havia sofrido acidentes de trabalho anteriormente (até nove vezes). Apenas 35\% dos trabalhadores entrevistados haviam sofrido apenas um acidente. Não foi observada associação estatística entre a quantidade de acidentes sofrida pelos trabalhadores e a idade na ocorrência do acidente $(\mathrm{p}=0,370)$.

Tabela 3. Intensidade sonora nos postos de trabalho dos acidentados, no período de 2004 a 2006 ( $\mathrm{n}=336$ ).

\begin{tabular}{lcccc}
\hline $\begin{array}{c}\text { Intensidade sonora } \\
\text { (dBA) }\end{array}$ & Freq. absoluta & Freq. relativa \% & $\begin{array}{c}\text { Freq. absoluta } \\
\text { acumulada }\end{array}$ & $\begin{array}{c}\text { Freq. rel. } \\
\text { acumulada \% }\end{array}$ \\
\hline Menos de 85 & 30 & 8,9 & 30 & 8,9 \\
De 85 a 90 & 153 & 45,5 & 183 & 54,4 \\
Mais de 90 & 153 & 45,5 & 336 & 100 \\
Total & 336 & 100 & - & - \\
\hline
\end{tabular}

Fonte: PPRA da empresa.

Tabela 4. Caracterização da reincidência de acidentes maior que três, no período estudado, na empresa $(n=8)$.

\begin{tabular}{lccl}
\hline Sujeito & Número de acidentes & NPS $(\mathbf{d B A})$ & \multicolumn{1}{c}{ Função } \\
\hline 1 & 5 & 90,9 & Operador de máquina \\
2 & 4 & 91,6 & Caldeireiro \\
3 & 4 & 91,6 & Caldeireiro \\
4 & 3 & 91,6 & Praticante caldeireiro \\
5 & 3 & 91,6 & Caldeireiro \\
6 & 3 & 87,5 & Mecânico manutenção \\
7 & 3 & 91,6 & Caldeireiro \\
8 & 3 & 91,6 & Caldeireiro \\
\hline
\end{tabular}


A percepção dos trabalhadores em relação à intensidade do ruído ao qual estão expostos quotidianamente foi considerada como forte em 96 trabalhadores (57,2\%); 63 (38\%) consideraram como de média intensidade e 7 (4,2\%) como de fraca intensidade. E no momento do acidente, a percepção da intensidade do ruído foi forte para $51(30,7 \%)$ trabalhadores, $72(43,3 \%)$ como média, $20(12,1 \%)$ como fraca, $9(5,4 \%)$ não se lembram e $14(8,5 \%)$ não responderam. Entre os trabalhadores, 98 (59\%) relataram que o ruído no local de trabalho causava incômodo. Não houve, porém, associação entre o NPS avaliado do posto de trabalho e a percepção do trabalhador com a gravidade do acidente.

Quanto ao nível de ruído medido nos postos de trabalho, relacionado com o número de acidentes, observaram-se os dados reunidos na Tabela 5 .

Conforme aumenta a intensidade sonora, aumenta a proporção de trabalhadores acidentados, porém não se encontrou associação estatística entre essas variáveis $(\mathrm{p}=0,641)$.

Todos os trabalhadores utilizavam protetor auricular durante a jornada de trabalho, inclusive no momento do acidente.

\section{Etapa 3: resultados dos grupos focais}

No ano de 2004, foram três reuniões envolvendo um total de 29 acidentados (27,3\%), enquanto em 2005 foram quatro reuniões com 39 participantes $(30,9 \%)$ e, em 2006, cinco reuniões com 43 participantes $(41,3 \%)$. Participaram dos grupos 111 trabalhadores (pouco mais de 33\% do total), adesão aceitável ante a voluntariedade da atividade.

A análise do discurso dos trabalhadores possibilitou identificar as categorias causais dos acidentes e sugestões de prevenção, divididos em conjuntos temáticos e subdivisões, descritos a seguir:

Tabela 5. Número de acidentes sofridos pelos trabalhadores em razão do nível de pressão sonora do posto de trabalho $(n=166)$.

\begin{tabular}{lccccrr}
\hline $\begin{array}{l}\text { Nível de ruído } \\
\text { (dBA) }\end{array}$ & \multicolumn{2}{c}{ Acidentes sofridos } & & \multicolumn{2}{c}{ Total } \\
\cline { 2 - 3 } \cline { 6 - 7 } & De 1 a 3 & Mais de 3 & & n & \% \\
\hline Menor que 85 & 9 & 2 & & 11 & 6,6 \\
De 85 a 90 & 57 & 10 & & 67 & 40,3 \\
Mais de 90 & 65 & 23 & & 88 & 53 \\
Total & 131 & 35 & & 166 & 100 \\
\hline
\end{tabular}

(A) Riscos devido às condições de trabalho e por fatores pessoais: refere-se à percepção dos trabalhadores sobre os riscos de acidentes em razão do ambiente de trabalho, tanto os físicos quanto aqueles proporcionados por equipamentos e ferramentas, por equipamentos de proteção inadequados e a atribuição do acidente a fatores pessoais. Pôde-se organizá-los em subtemas: agentes físicos incômodos, ferramentas e equipamentos insuficientes ou sem condições de uso, equipamentos de proteção individual inadequada e fatores pessoais.

(A.1) Agentes físicos incômodos (AO, 47 anos, caldeireiro): O ruído também atrapalha; (EC, 48 anos, soldador): É muito ruído, fica meio tonto; (JB, 45 anos, caldeireiro): O ruído tira a concentração, deixa irritado e estressado e acho que ajuda nos acidentes.

(A.2) Ferramentas e equipamentos insuficientes ou sem condições de uso: (OV, 47a, caldeireiro): O cara põe excesso de carga na ponte-rolante, ele sabe qual é o limite, mas põe a mais, o chefe diz: pode pôr, aguenta! Às vezes não aguenta, né?; (AC, 47a, caldeireiro): Meu acidente foi no punho, cortei por falta de uma escada no setor, agora tem escada; espera acontecer o problema pra depois resolver; (FM, 42a, caldeireiro): Tive que fazer uma ferramenta porque o colega estava usando a que eu precisava, só que não era tão forte e quebrou batendo no meu rosto; (LO, 36a, caldeireiro): Tem que improvisar muito nas ferramentas, o tempo todo, daí quando o improviso dá certo, tudo bem, quando dá errado e causa acidente todo mundo dá palpite e diz como deveria ter feito.

(A.3) Equipamentos de proteção individual inadequados: (WP, 32a, caldeireiro): Esses óculos de segurança são fracos, não aguentam os cavacos, vive quebrando, daí vem o acidente; (AS, 40a, maçariqueiro): Tem EPI que não está bom, é uniforme que rasga, óculos que fica riscado e só pode trocar depois de um ano.

(A.4) Fatores pessoais: (CR, 18a, caldeireiro): Algumas pessoas não tomam os cuidados que poderiam, não usam os EPI corretamente, porque não querem; (PS, 51a, caldeireiro): Muitos novos se acidentam porque não têm experiência de como fazer ou não sabe se dará certo daquele jeito; (EC, 38a, soldador): Mas os velhos também se acidentam, é autoconfiança, acha que já sabe tudo, já habituou, e relaxa mais.

(B) Riscos relativos à organização do trabalho: englobam os fatores de riscos de acidentes referentes à divisão das tarefas e das pessoas, que são percebidos como interferência negativa para os trabalhadores, com os subtemas: pressão tem- 
poral da chefia, falta de planejamento e de treinamento, número insuficiente de trabalhadores e horas extras.

(B.1) Pressão temporal da chefia: (CR, 18a, caldeireiro): O chefe define o tempo de trabalho, ele exige o máximo das pessoas; (AS, 40a, maçariqueiro): A pressão de produção depende do chefe; se é mais rigoroso, controla as pausas; (JV, 46a, caldeireiro): Tem prazo para entregar apertado, o navio fica no porto com data para sair com a produção, daí o chefe aperta; (JS, 43a, soldador): Cada um dá seus pulos pra adiantar o serviço e os chefes fazem vista grossa, até que acontece alguma coisa, então caem em cima.

(B.2) Falta de planejamento e de treinamento: (WP, 32a, caldeireiro): Quando tive que mudar o tipo de serviço que estava acostumado a fazer, aí não tinha certeza se dava certo e me acidentei; (MC, 41a, caldeireiro): Tem que ter treinamento para usar a ponte rolante, mas não tem gente suficiente com treinamento, então todo mundo acaba usando; (DP, 23a, operador de máquina): Falta planejamento de fábrica, só se planeja a carga horária; agora, como você vai fazer e de que forma, é problema seu.

(B.3) Número insuficiente de trabalhadores e horas extras: (EC, 38a, soldador): Tem que fazer rápido, mas não tem ajudante, daí o funcionário tem que fazer tudo; (ES, 24a, caldeireiro): Agora tem uma maior exigência de produção e aumentaram as horas extras, que vai pro banco de horas, então é um excesso de trabalho sem tempo para descansar.

(C) Riscos por fatores psicossociais: englobam a visão dos trabalhadores sobre aspectos não relacionados ao desenvolvimento da sua atividade profissional no ambiente de trabalho, mas estão a estes relacionados, e que interferem na atividade laboral, podendo configurar-se como fator de risco para acidentes. (JB, 45a, caldeireiro): Outra coisa também são os problemas pessoais, o que se traz de casa pode afetar [...] devido à situação financeira; (AR, 42a, soldador): A falta de dinheiro deixa o cara nervoso e distraído, e ele se acidenta; (AA, 26a, praticante de caldeireiro): Muita gente vem estressado de casa, não consegue separar as coisas, e aí pode sofrer mais acidentes; (RS, 23a, furador): A desatenção é um problema; se a pessoa vem preocupada, se não dormiu direito, o cérebro fica mais lento e aí acontece.

(D) Ações para evitar os acidentes: reúnem aspectos que possibilitam identificar algumas concepções, preocupações, cuidados, práticas e expectativas em relação à prevenção dos acidentes de trabalho, organizados em subtemas: su- porte emocional e valorização dos trabalhadores; melhoria nos EPI; melhores estratégias de organização do trabalho, melhoria nas condições de trabalho, valorização da Cipa.

(D.1) Suporte emocional e valorização dos trabalhadores: (JB, 45a, caldeireiro): Precisava de uma psicóloga na empresa para auxiliar os trabalhadores e os encarregados. Os encarregados deveriam fazer curso para serem mais humanos; (PZ, 44a, caldeireiro): Precisava ter mais cuidado com os problemas psicológicos da gente, isso influencia, é pressão, é estresse.

(D.2) Melhorias nas estratégias de organização do trabalho: (DP, 23a, operador de máquina): Precisava de maior conscientização da engenharia de produção do tempo para poder trabalhar, porque sempre atrasa a entrega da matériaprima e não desconta esse tempo na produção; (JC, 20a, operador de máquina): Não vai resolver aumentar o número de pessoas, tem que fazer um planejamento de produção.

(D.3) Melhorias nas condições de trabalho: (JM, 34a, operador de dobradeira): Precisa melhorar a manutenção de alguns equipamentos, a ponte-rolante está com conservação ruim. Precisava ter manutenção sempre, não só quando quebra.

(D.4) Valorização da Cipa: (AO, 47a, caldeireiro): Precisa dar mais autonomia pros cipeiros trabalharem, inclusive de paralisar qualquer máquina sem condição.

\section{Discussão}

O estudo de caso foi desenvolvido em uma empresa metalúrgica localizada num município do interior de São Paulo. Este município apresentou uma incidência dos acidentes de trabalho em torno de $3,8 \%$, para o período estudado $(77,7 \%$ foram leves e $19,6 \%$ de gravidade moderada), investigados nos prontos-socorros da cidade ${ }^{21}$.

A incidência de acidentes (Tabela 1) na empresa estudada foi maior do que no município todo. Isto ocorreu pois não há a notificação por parte da empresa da totalidade das ocorrências, registrando nos órgãos oficiais somente daqueles acidentes com afastamento.

Já é fato que as estimativas de subnotificação dos acidentes aos órgãos públicos podem chegar a $76,6 \%{ }^{14,15}$. A recusa por parte dos empregadores em notificar os acidentes através da CAT é comum, assim como também é comum a dificuldade de acesso a arquivos das indústrias pelos auditores fiscais e profissionais da vigilância em saúde do trabalhador, obstruindo o conhecimento 
da real situação no país ${ }^{14,17}$. Essa atitude por parte dos empregadores prejudica os trabalhadores e a definição de políticas públicas que proporcionem a defesa da qualidade de vida no trabalho.

Como a empresa estudada possui um Serviço de Segurança e Medicina do Trabalho próprio, os acidentes não são encaminhados aos serviços públicos, dificultando seu registro, pois são equacionados internamente ou na sua rede conveniada.

Os tipos de lesões encontradas na empresa estudada foram predominantemente contusões e ferimentos corto-contusos. O seu PPRA já indicava como agentes de riscos mecânicos as batidas, cortes, prensamentos, impacto de objetos e a existência de máquinas ou equipamentos sem proteção, associados às lesões encontradas, porém sem um plano efetivo para solucionar tais situações, apenas recomendando o uso de equipamentos de proteção individual e a observação das recomendações de segurança, que demonstraram não terem sido suficientes em face da quantidade de acidentes. Essa situação é encontrada em diversas empresas, nas quais são desenvolvidas "práticas de gestão de riscos e prevenção" limitadas por questões econômicas e pela concepção de que o acidente ocorre por um ato inseguro do trabalhador, daí as ações preventivas seriam a difusão e o treinamento do uso de equipamentos de proteção individual e programas de conscientização visando a um comportamento seguro no trabalho ${ }^{22}$.

Houve predomínio dos acidentes no período diurno (manhã) de trabalho. Estudo nos Estados Unidos encontrou maior risco de se acidentar associado ao trabalho no turno noturno, considerando que o trabalhador encontra-se mais cansado e sonolento no turno noturno, portanto mais propenso ao acidente ${ }^{23}$. Porém, o ritmo de trabalho no período diurno é mais intenso, levando a acidentes, e a troca do turno pela manhã pode gerar mais acidentes ${ }^{24}$.

O ruído intenso figura nos documentos da empresa como um agente de risco importante no ambiente de trabalho, mas a única medida de controle de ruído adotada é a utilização de protetores auriculares.

Menos de $10 \%$ do total dos trabalhadores acidentados (Tabela 3) trabalhavam em ambientes com ruído inferior a $85 \mathrm{dBA}$, portanto, a maioria dos trabalhadores estava exposta a intensidades sonoras que obrigam a adoção de medidas corretivas imediatas, segundo a Norma de Higiene Ocupacional $n^{\circ} 1^{25}$.

Ainda persistem nos meios industriais, mesmo com todo o avanço legal e de segurança no trabalho, níveis de ruído considerados prejudiciais à saúde e que demandam uma ação corretiva imediata. A legislação sobre o controle coletivo do ruído não vem sendo adequadamente cumprida, persistindo os níveis de pressão sonora considerados insalubres à saúde, e é a adoção de protetores auriculares a única ação preventiva ${ }^{26}$.

Os trabalhadores acidentados estavam utilizando protetores auriculares também no momento do acidente, atitude que poderia ser um fator de proteção para a ocorrência do acidente do trabalho, considerando-se o ruído como um fator importante na acidentabilidade. Porém, estudo nos Estados Unidos demonstrou que o uso de protetores auriculares, principalmente entre aqueles que já possuem uma alteração auditiva, pode ser fator de risco para os acidentes ${ }^{27} . \mathrm{Na}$ empresa estudada, mesmo utilizando protetores auriculares (100\% de uso), a ocorrência de acidentes foi elevada, e a prevalência de alterações auditivas (de origem ocupacional ou não) foi em torno de $42 \%$ entre os acidentados, o que poderia influenciar nos acidentes. Há referências sobre a associação entre o risco de se acidentar e a combinação entre os fatores exposição ao ruído intenso e possuir a perda auditiva induzida por ruído, em trabalhadores ${ }^{27,28}$.

Através da análise quantitativa não foi possível relacionar a exposição ao ruído intenso com os acidentes de trabalho, mesmo observando-se que nos casos de reincidência de acidentes superiores a três vezes os níveis de pressão sonora estavam acima de 87,5 dBA.

Os trabalhadores desse estudo expostos a níveis de pressão sonora mais intensos (maiores de 90 dBA) apresentavam maior ocorrência de acidentes (53\%), o que pode ser indicativo de um ambiente de trabalho mais hostil, considerandose todos os riscos possíveis envolvidos. Estudos ${ }^{29,30}$ encontraram duas vezes mais riscos de se acidentar entre trabalhadores que relataram trabalhar expostos ao ruído intenso, porém não mensuraram o ruído, apenas consideraram o referido pelo trabalhador (subjetivo). No presente estudo, mesmo com dados objetivos dos níveis de ruído, considerou-se também a percepção do trabalhador sobre a intensidade sonora. A maioria dos trabalhadores $(57,2 \%)$ referiu considerar o ruído no seu trabalho como de forte intensidade e incômodo (59\%), porém, referiram que no momento do acidente a intensidade sonora era média para a maioria $(43,3 \%)$, o que parece um contrassenso, mas pode indicar que o trabalhador não está associando seu acidente ao fator ruído. O questionário por si só não conseguiu justificar esses dados. 
O grau de escolaridade do grupo de trabalhadores que respondeu ao questionário foi de 8,8 anos em média. A política da empresa adotada há alguns anos é de somente contratar trabalhadores que tenham no mínimo oito anos de escolaridade (ensino fundamental completo). Os acidentes acometeram principalmente os caldeireiros $(48,2 \%)$ e os soldadores $(21,4 \%)$, que são profissões especializadas que exigem a capacitação do trabalhador em cursos profissionalizantes, além de experiência prática nessas funções, por apresentam exigências cognitivas e um saber específico. Há na empresa um contingente maior dessas funções. Os trabalhadores acidentados estudados apresentavam um nível educacional considerado mediano, então a falta de informação ou a dificuldade em compreender as regras de segurança não deveria ser um fator de risco de acidente. Um estudo no Brasil observou que trabalhadores com menos tempo de escolaridade se acidentam com mais frequência ${ }^{29}$. E nos Estados Unidos, estudo encontrou forte associação entre o risco de se acidentar e o baixo grau de escolaridade ( $\mathrm{RR}=7,38,95 \%$ IC 3, 6414,98), em trabalhadores de diferentes setores ${ }^{23}$.

A faixa etária que apresentou maior ocorrência de acidentes neste estudo foi de 31 a 50 anos $(55,4 \%)$, ou seja, trabalhadores com certa experiência. Outros estudos também encontraram uma maior ocorrência de acidentes entre homens nas faixas a partir dos 30 anos de idade, coincidindo com a faixa etária do grupo estudado ${ }^{16,23,29}$.

A maioria dos trabalhadores entrevistados $(64,5 \%)$ já havia sofrido mais de um acidente, demonstrando uma grave questão: a reincidência, que não se justifica pela faixa etária dos trabalhadores (não há associação estatística $\mathrm{p}=0,370$ ). A reincidência é um sinal importante da presença de uma disfunção severa que está expondo intensamente o trabalhador ao risco.

A exposição aos riscos tradicionalmente identificados na literatura, como idade, grau de escolaridade, exposição ao ruído e turno de trabalho, não foram capazes por si só de explicarem os altos índices de acidentes e a reincidência encontrados neste estudo. O perfil do acidentado deste estudo é predominantemente mais experiente (31 a 50 anos), com bom grau de escolaridade $(8,8$ anos), pertencente ao turno diurno, e está exposto ao ruído. Estas constatações poderiam nortear ações eficazes para a prevenção dos acidentes?

Outras situações, consideradas determinantes tecnológicos e sociais, foram identificadas nos discursos dos trabalhadores e aparecem como prováveis geradores dos acidentes e que, junta- mente com os dados quantitativos, auxiliam na compreensão dos acidentes na empresa, definindo ações preventivas.

A análise da percepção dos trabalhadores pelo Grupo Focal permitiu identificar atitudes, sentimentos e ideias a respeito dos acidentes de trabalho ocorridos na empresa, auxiliando a compreensão da situação na fábrica.

Foi possível identificar duas categorias de análises (causas dos acidentes e sugestões de prevenção), que foram divididas em conjuntos temáti$\cos$ (riscos relacionados às condições de trabalho, riscos relativos à organização do trabalho, riscos por causas externas à atividade de produção, ações para evitar os acidentes, melhorias nas estratégias de organização do trabalho, melhorias nas condições de trabalho e valorização da Cipa).

Pelos depoimentos dos trabalhadores, múltiplos fatores colocam em risco a sua saúde física e mental, o que pode levar ao acidente. Há o relato de uma constante "pressão" sobre o trabalhador, partindo das chefias, para que a produção ocorra num tempo menor, com um número reduzido de pessoal ou mesmo com pessoas não qualificadas para a função. Essa pressão foi referida durante o Grupo Focal e se caracteriza como pressão hierárquica proveniente das relações com a chefia, pressão pela falta de qualificação que obriga trabalhadores não qualificados a realizarem tarefas diversas, pressão de produtividade que definem metas de produção em tempos preestabelecidos nem sempre possíveis ${ }^{31}$. Na empresa estudada, no turno noturno não há a presença de chefia e as metas de produção são mais flexíveis, o que poderia também justificar os menores índices de acidentes à noite.

Aliado à pressão, observou-se o relato sobre o estado precário de ferramentas e equipamentos, a manutenção e conservação insuficientes e até mesmo a sua ausência. Em algumas situações o trabalhador tem que optar por uma ação contrária às normas de segurança, mas que garanta a continuidade da tarefa e não interrompa a produção, com a conivência do próprio chefe. O problema não é a falta da ferramenta ou equipamento em si, mas o improviso que isso gerou, conforme relatos, e que expôs o trabalhador ao acidente. Tal situação já foi observada em outros estudos, que afirmaram ser a análise clássica dos acidentes insuficiente para a identificação dessa questão, ou seja, que muitas vezes, para a realização da tarefa e dos objetivos da produção, o trabalhador precisa infringir as normas de segurança ${ }^{22,32,33}$.

Os riscos relativos à organização do trabalho, como o planejamento da produção, foram 
evidenciados no discurso dos trabalhadores participantes dos grupos focais, revelando uma situação na empresa que dificulta a atividade de trabalho e leva aos acidentes. Outros autores já identificavam falhas gerenciais e da organização do trabalho como fatores desencadeadores de acidentes de trabalho ${ }^{3,34}$.

Tais situações nos remetem à noção de acidente organizacional proposto por James Reason ${ }^{35}$, na qual se podem observar os "erros latentes", de consequências latentes e que podem permanecer por muito tempo no sistema produtivo até que desencadeiam um acidente, considerado um "erro ativo" (de consequência imediata). Os erros latentes são cometidos pelos responsáveis pelo planejamento, pelos gerentes e responsáveis, quando falham na concepção do sistema produtivo e colocam em risco os trabalhadores fabris, cuja falha terá consequências imediatas, o acidente ${ }^{36}$.

Alguns trabalhadores reconhecem as questões econômicas e sociais como influenciando no trabalho, o que contribuiria para os acidentes. As preocupações em relação aos salários baixos e ao medo do desemprego predispõem a uma condição emocional que pode contribuir para a ocorrência dos acidentes. As atuais modificações no mundo do trabalho têm contribuído para os problemas de saúde mental ${ }^{34}$.

O relato de grande parte dos trabalhadores apontou como explicações para os acidentes o ritmo de trabalho, os problemas de ordem organizacional do trabalho e os fatores emocionais relacionados com o próprio trabalho (estresse, ruído, problemas econômicos), desvinculados das ideias clássicas sobre a culpabilidade da vítima e a naturalização do acidente. Porém, para alguns trabalhadores, principalmente entre os mais jovens, observou-se ainda a associação do acidente a um descuido no desempenho da sua atividade, apontando a autoconfiança, a incerteza diante de uma nova tarefa, a falta de cuidado, a inexperiência e a desatenção como causas dos acidentes, dando a entender que poderiam gerar "atos inseguros" nos trabalhadores. Outro estudo em metalúrgica constatou no discurso dos trabalhadores a crença de que os acidentes são naturais e inevitáveis e a explicação deles como atos inseguros, porém ocorreram algumas rupturas nesse discurso por parte de alguns trabalhadores questionando essa abordagem ${ }^{22}$.

Através dos grupos focais, algumas sugestões para o equacionamento dos problemas foram referidas pelos próprios trabalhadores, como melhorias nas condições e organização do trabalho e maior valorização do trabalhador. Alguns trabalhadores percebem que os acidentes são evitáveis e existem maneiras de diminuí-los, porém estão fora do alcance da capacidade de resolutividade dos próprios trabalhadores, pois dependem da empresa (suporte ao trabalhador, mudanças organizacionais, melhorias nos equipamentos e valorização da Cipa).

\section{Conclusão}

Conclui-se que há fatores de riscos ambientais para os acidentes como o ruído e o maquinário sem proteção, mas os relatos dos trabalhadores desvelaram determinantes tecnológicos e sociais que não apareceriam numa investigação clássica e que justificariam os acidentes e sua reincidência na empresa, numa análise global.

Quando a compreensão dos acidentes de trabalho rompe com o enfoque clássico que culpa os trabalhadores acidentados por seus atos inseguros, outros fatores podem ser identificados que desvelam problemas na própria organização e que são precursores primários desses acidentes.

Através dos grupos focais, foi possível identificar mais claramente os prováveis fatores que contribuíam para os acidentes de trabalho na empresa, evidenciando uma disfunção organizacional, principalmente.

Mesmo identificando situações de risco para os acidentes de trabalho, os trabalhadores se submetem a elas, provavelmente pelo contexto social atual no qual estar empregado, mesmo em precárias condições, já é uma situação de privilégio.

A prevenção dos acidentes de trabalho na empresa estudada deve ser pensada a partir de mudanças organizacionais, iniciando-se pela abertura de um canal de comunicação com os próprios trabalhadores, como atores sociais. Fazem-se necessárias mudanças nas relações de trabalho, incluindo o trabalhador como ativo nesse processo, participando, inclusive, das tomadas de decisões dos gestores que interfiram diretamente na sua atividade. A estruturação de uma comissão para análise do trabalho na empresa, dentro de uma concepção ampla do processo saúde-doença-trabalho, identificaria melhor as situações problemáticas e definiria a sua solução. 


\section{Colaboradores}

CGO Gonçalves participou da coleta e análise dos dados e redação do artigo; A Dias participou da análise dos dados e da redação do artigo.

\section{Referências}

1. Pizzatto E, Garbin CAS, Amadei M. Perfil dos acidentes do trabalho ocorridos no município de Araçatuba-SP nos anos de 2000 e 2001. Revista Brasileira de Saúde Ocupacional 2004; 29(11):57-62.

2. Dwyer T. Life and death at work: industrial accidents as a case of socially produced error. New York: Plenum Press; 1991.

3. Binder MCP, Almeida IM. Estudo de caso de dois acidentes do trabalho investigados com o método de árvores de causas. Cad Saude Publica 1997; 13(4):749-760.

4. Vilela RAG. Acidentes do trabalho com máquinas: identificação de riscos e prevenção. São Paulo: CUT; 2000.

5. Brasil. Ministério do Trabalho. Saúde e segurança: análises de acidentes - análises. [site da Internet] 2002 [acessado 2007 ago 25]. Disponível em: http:/ /www.mte.gov.br

6. Dias EA. O manejo de agravos à saúde relacionados com o trabalho. In: Mendes R. Patologia do trabalho. São Paulo: Atheneu; 1997. p. 59-85.

7. Binder MCP, Almeida IM, Monteau M. Árvore de causas: método de investigação de acidentes de trabalho. São Paulo: Publish do Brasil; 1995.

8. Minayo-Gomez C, Thedin-Costa SMF. A construção do campo da saúde do trabalhador: percurso e dilemas. Cad Saude Publica 1997; 13(Supl.2):21-32.

9. Mendes R, Dias EC. Da medicina do trabalho à saúde do trabalhador. Rev Saude Publica 1991; 25(5):341-349.

10. Mendes JMR, Wünsch DS. Elemento para uma nova cultura em segurança e saúde no trabalho. Rev Bras Saúde Ocupacional 2007; 32(115):154-163.

11. Machado JMH. Processo de vigilância em saúde do trabalhador. Cad Saude Publica 1997; 13(Supl.2):33-46.

12. Alves S, Luchesi G. Acidentes do trabalho e doenças profissionais no Brasil: a precariedade das informações. Informe Epidemiológico do SUS 1992; 3:7-19.

13. Binder MCP, Cordeiro R. Sub-registro de acidentes de trabalho em localidade do estado de São Paulo. Rev Saude Publica 2003; 37(4):409-416.

14. Correa PRC, Assunção AA. A subnotificação de mortes por acidentes de trabalho: estudo em três bancos de dados. Epidemiologia e Serviços de Saúde 2003; 12(4):203-212.

15. Cordeiro R, Sakate M, Clemente APG, Diniz CS, Donalisio MR. Subnotificação de acidentes do trabalho não fatais em Botucatu-SP, 2002. Rev Saude Publica 2005; 39(2):254-260.

16. Cordeiro R, Prestes SCC, Sakate M, Clemente APG, Diniz CS, Donalisio MR. Incidência de acidentes do trabalho não fatais em localidade do Sudeste do Brasil. Cad Saude Publica 2006; 22(2):387-393.

17. Salvador L. Acidente do trabalho: empregador que não emite a CAT deve indenizar trabalhador pelos prejuízos. Jus Navigandi [periódico na Internet] 2004 out [acessado $2008 \mathrm{fev} \mathrm{12]}$; 8(463). [cerca de 12p.] Disponível em: http://jus2.uol.com.br/doutrina/texto.asp?id $=5802$

18. Gustafson TL. True Epistat: standard version. Richardson: Epistat Services; 1991. 
19. Basch CE. Focus group interview: an underutilized research technique for improving theory and practice in health education. Health Education Quarterly 1987; 14(4):411-448.

20. Fontes OI, Motta DG, Monteiro MI, Zuccolotto DG, Silva RC, Morgan D, Andrade FME, Rodrigues G, Souza FC, Bovo FCB. Formando recursos humanos para o SUS: relato de uma experiência interdisciplinar. Saúde em Revista 2003; 5(11):21-28.

21. Cordeiro R, Vilela RAG, Medeiros MAT, Gonçalves CGO, Bragantini CA, Varolla AJ. O sistema de vigilância de acidentes de trabalho de Piracicaba, São Paulo, Brasil. Cad Saude Publica 2005; 21(5):15741583.

22. Oliveira F. A persistência da noção de ato inseguro e a construção da culpa: os discursos sobre os acidentes de trabalho em uma indústria metalúrgica. Rev Bras Saúde Ocupacional 2007; 32(115):19-27.

23. Swaen GMH, van Amelsvoort LGPM, Bültmann U, Kant IJ. Fatigue as a risk factor for being injured in an occupational accident: results from the Maastricht Cohort Study. Occupational and Environmental Medicine 2003; 60(Supl.1):88-92.

24. Rumin CR, Schmidt MLG. Influências das condições e organização do trabalho de uma indústria de transformação de cana-de-açúcar na ocorrência de acidentes de trabalho. Saúde e Sociedade 2008; 17(4):56-67.

25. Fundacentro. Norma de higiene ocupacional: procedimento técnico para avaliação da exposição ocupacional ao ruído. São Paulo: Fundacentro; 2001. (Norma de Higiene Ocupacional, $\mathrm{n}^{\circ} 1$ ).

26. Gonçalves CGO, Iguti AM. Análise de programas de preservação da audição em quatro indústrias metalúrgicas de Piracicaba, São Paulo, Brasil. Cad Saude Publica 2006; 22(3):609-618.

27. Van Charante AWM, Mulder PGH. Perceptual acuity and the risk of industrial accidents. American Journal of Epidemiology 1990; 131(4):652-663.

28. Picard M, Girard A, Simard M, Larocque R, Lerox T, Turcotze F. Accident analysis and prevention 2008; 40:1644-1652.

29. Lima RC, Victora CG, Dall'Agual MM, Facchini LA, Fassa AG. Percepção de exposição a cargas de trabalho e riscos de acidentes em Pelotas, RS. Rev Saude Publica 1999; 33(2):12-46.
30. Dias A, Cordeiro R, Gonçalves CGO. Exposição ocupacional ao ruído e acidentes de trabalho. Cad Saude Publica 2006; 22(10):2125-2130.

31. Schmidt MLG. O mundo do trabalho: o psicodrama como instrumento de diagnóstico da influência da organização do trabalho na saúde dos trabalhadores [tese]. Campinas: Faculdade de Ciências Médicas; 2003.

32. Almeida IM, Jackson Filho JM. Acidentes e sua prevenção. Rev Bras Saúde Ocupacional 2007; 32(115):7-18.

33. Câmara GR, Assunção AA, Lima FPA. Os limites da abordagem clássica dos acidentes de trabalho: o caso do setor extrativista vegetal em Minas Gerais. Rev Bras Saúde Ocupacional 2007; 32(115):41-53.

34. Sato L, Bernardo, LH. Saúde mental e trabalho: os problemas que persistem. Cien Saude Colet 2005; 10(4):869-878.

35. Reason J. Human error. $2^{\text {a }}$ ed. London: Cambride University Press; 1999.

36. Vilela RAG, Mendes RWB, Gonçalves CAM. Acidente do trabalho investigado pelo Cerest Piracicaba: contrapondo a abordagem tradicional da segurança do trabalho. Rev Bras Saúde Ocupacional 2007; 32(115):29-40.

Artigo apresentado em 19/12/2007

Aprovado em 16/03/2009

Versão final apresentada em 16/04/2009 